\title{
Aviation Model: A Fine-Scale Numerical Weather Prediction System for Aviation Applications at the Hong Kong International Airport
}

\author{
Wai-Kin Wong, ${ }^{1}$ Cheong-Shing Lau, ${ }^{2}$ and Pak-Wai Chan ${ }^{1}$ \\ ${ }^{1}$ Hong Kong Observatory, Hong Kong \\ ${ }^{2}$ Department of Computing, Polytechnic University of Hong Kong, Hong Kong \\ Correspondence should be addressed to Pak-Wai Chan; pwchan@hko.gov.hk
}

Received 29 December 2012; Revised 16 April 2013; Accepted 22 May 2013

Academic Editor: Richard Leaitch

Copyright (C) 2013 Wai-Kin Wong et al. This is an open access article distributed under the Creative Commons Attribution License, which permits unrestricted use, distribution, and reproduction in any medium, provided the original work is properly cited.

\begin{abstract}
The Hong Kong Observatory (HKO) is planning to implement a fine-resolution Numerical Weather Prediction (NWP) model for supporting the aviation weather applications at the Hong Kong International Airport (HKIA). This new NWP model system, called Aviation Model (AVM), is configured at a horizontal grid spacing of $600 \mathrm{~m}$ and $200 \mathrm{~m}$. It is based on the WRF-ARW (Advance Research WRF) model that can have sufficient computation efficiency in order to produce hourly updated forecasts up to 9 hours ahead on a future high performance computer system with theoretical peak performance of around 10 TFLOPS. AVM will be nested inside the operational mesoscale NWP model of $\mathrm{HKO}$ with horizontal resolution of $2 \mathrm{~km}$. In this paper, initial numerical experiment results in forecast of windshear events due to seabreeze and terrain effect are discussed. The simulation of sea-breeze-related windshear is quite successful, and the headwind change observed from flight data could be reproduced in the model forecast. Some impacts of physical processes on generating the fine-scale wind circulation and development of significant convection are illustrated. The paper also discusses the limitations in the current model setup and proposes methods for the future development of AVM.
\end{abstract}

\section{Introduction}

The Hong Kong International Airport [1] is located near the Lantau Island where airflow disturbances are generated due to the complex mountainous orography. Mountains with summits of close to $1000 \mathrm{~m}$ above ground level (AGL) and valleys of altitudes at around $400 \mathrm{~m}$ are found about $4 \mathrm{~km}$ to the southeast of HKIA. Terrain-disrupted airflow could occur over and around HKIA when the prevailing winds are from east to southwest, in particular when strong-eastto-southeasterly winds blow over the airport in the spring under a stable boundary layer. Also, a sea-breeze circulation is commonly formed during the late morning due to insolation under synoptic weather patterns for formation of light to moderate north-to-northwesterly winds. Wind convergence and disturbance result in low-level windshear and turbulence [1].

In summer, significant convection systems or organized thunderstorms affecting HKIA and the Hong Kong Flight Information Region (HKFIR) (Figure 1) lead to disruption in air traffic for in-bound and out-bound flights. Moreover, the airfield operation will be greatly affected by widespread or prolonged thunderstorms and lightning. Hence, it is particularly essential to provide accurate forecast of the timing and severity of the convective weather to the aviation users such as the Air Traffic Control to assure efficiency and safety of flights and airfield operations, as well as to reduce flight delays and diversions, and to maximize capacity and optimize the flow of air traffic within the HKFIR.

Currently in HKO, the mesoscale NWP model system, namely, the AIR/NHM [2] using the Nonhydrostatic Model of the Japan Meteorological Agency (JMA-NHM [3]), provides hourly updated model forecasts with horizontal resolution at $2 \mathrm{~km}$ (referred as the $2 \mathrm{~km} \mathrm{NHM}$ hereafter). Observations from mesoscale observation networks such as the automatic weather stations over Hong Kong and Guangdong and ground-based remote sensing data such as radar, wind profiler, and GPS total precipitable water vapour are assimilated in the 3-dimensional variational data assimilation (3DVAR) system. Radar Doppler velocity and retrieved wind data using 

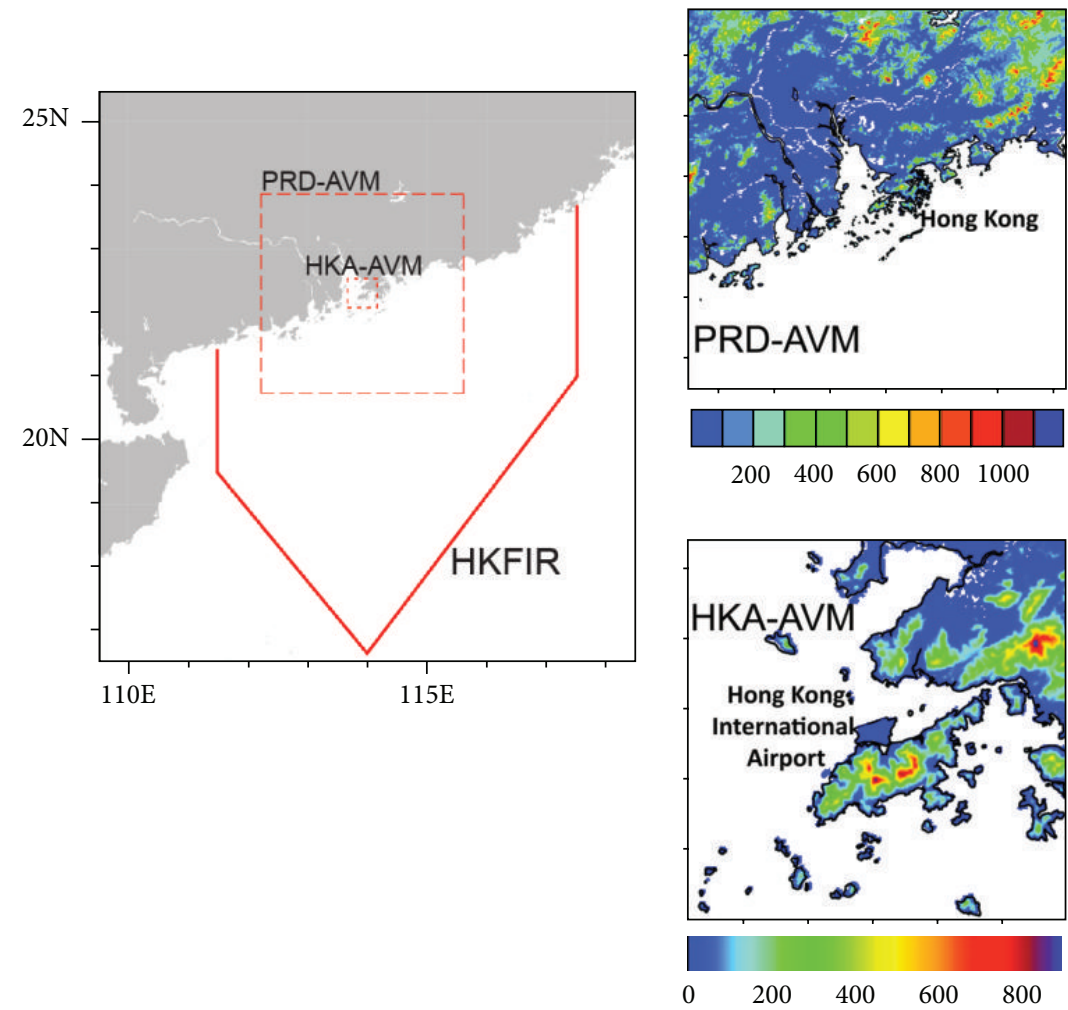

FIGURE 1: Boundary of HKFIR and spatial coverage of PRD-AVM and HKA-AVM.

mosaic of radars in Hong Kong, Shenzhen, and Guangzhou are also assimilated in $2 \mathrm{~km}$ NHM to improve the short-term prediction of significant convection [4]. While in general the $2 \mathrm{~km}$ NHM can provide some useful guidance on the development of mesoscale weather features, it is inadequate to resolve the localized effects due to terrain over the Lantau Island and small scale land/sea contrast around the airport. Therefore, a fine-scale modeling system is needed to provide improved guidance on the formation of land/sea-breeze effects and other mesoscale phenomena.

In this paper, the development of the Aviation Model (AVM) system based on the Weather Research and Forecasting (WRF) model [5] is discussed. Section 2 introduces the general setup of AVM. Case studies of windshear are presented in Section 3 including description of impact of model tuning. Performance of AVM in forecasting of significant convection and impact of cloud microphysics schemes are described in Section 4. Concluding remarks, including the current limitations and possible development areas of AVM, are presented in Section 5.

\section{Design of the Aviation Model (AVM) System}

2.1. General Model Setup. AVM is based on the WRF-ARW (Advanced Research WRF) - the Eulerian mass-coordinate dynamical core. The initial setup of AVM, as presented in this paper, is based on version 3.2.1 (see Section 4). The whole AVM system consists of two domains with horizontal resolutions at $600 \mathrm{~m}$ and $200 \mathrm{~m}$ covering the Pearl River Delta
(PRD) and the HK Airport (HKA) areas. For brevity, they are referred as PRD-AVM and HKA-AVM. The spatial coverage of PRD-AVM (HKA-AVM) is about $350 \mathrm{~km}(50 \mathrm{~km})$ in both east-west and north-south directions (Figure 1). The AVM will be operated in hourly update basis: the initial condition of each hourly run of PRD-AVM is derived from the forecasts of $2 \mathrm{~km}$ NHM with a boundary update frequency of 1 hour. One-way nesting is adopted in which the initial and boundary conditions of HKA-AVM are obtained from the forecasts of PRD-AVM. The forecast ranges of PRD-AVM and HKAAVM are 9 hours.

For a better representation of near-surface weather conditions and boundary layer characteristics, about 15 vertical levels of data within $1000 \mathrm{~m}$ AGL of the model terrain are generated from $2 \mathrm{~km}$ NHM forecasts to produce the initial and boundary conditions of PRD-AVM. The orography used in both PRD-AVM and HKA-AVM is derived from the Shuttle Radar Topography Mission (SRTM) dataset (http://srtm.usgs.gov/) in 3 arc-second of horizontal resolution (approximately at $90 \mathrm{~m}$ ) in order to resolve spatial variation of the terrain height over Lantau and land-sea contrast in HKIA.

2.2. Model Physical Processes. In WRF-ARW, a number of options are available in each of the model physical processes to perform numerical simulations of atmospheric processes at different scales. For instance, one of the settings to run WRF-ARW for mesoscale weather simulation (and regional climate runs, see [6]) is based on the following: (NCAR 
Community Atmosphere Model) CAM or (Rapid Radiation Transfer Model) RRTM for longwave and shortwave radiation, Mellor-Yamada-Janjic (MYJ) planetary boundary layer (PBL), and surface layer process based on similarity theory adopted in Eta model. In MYJ scheme, which is a nonlocal PBL parameterization, Turbulence Kinetic Energy (TKE) is a prognostic variable, and cloud mixing effect is included to account for effects of cloud liquid water and cloud ice. The MYJ scheme was applied for a case study of terrain-induced windshear using a previous version of WRF-ARW (version 2.2) with horizontal resolution up to $200 \mathrm{~m}$. The simulated wind pattern was comparable to winds derived from LIDAR observations [1].

In the first configuration of AVM using WRF-ARW version 3.2.1, two-dimensional deformation ("km_opt" option in WRF) is chosen in order to provide consistent treatment with the selected planetary boundary layer process, as well as for estimate of computation resources required for realtime runs in hourly update basis. However, it will be shown in the following section that while the choice of options in the previous paragraph can generally produce features of mesoscale circulation leading to a sea-breeze-induced windshear, they are yet inadequate to predict fine-scale variation of temperature and wind in forecasting localized wind convergence over HKIA, where the terrain effect of Lantau may contribute to the formation. Thus, more recent physical parameterization schemes for shortwave and longwave radiation processes, PBL, land surface model, nearsurface physics, and more advanced numerical procedures to compute diffusion, heat flux, and moisture and momentum fluxes in WRF-ARW have been applied to investigate their impacts on the model simulation.

Given that the AVM is configured at subkilometre resolution, the cumulus parameterization scheme ("cu_physics" option) is turned off in both PRD-AVM and HKA-AVM. Explicit cloud microphysics using 5-class cloud microphysics (WSM5) was initially chosen in AVM using WRF-ARW version 3.2.1 as it has been widely adopted for numerical simulation of convective systems. The specific humidities of water vapour, cloud liquid water, rain water, cloud ice, and snow are prognostic variables in the model convective processes and grid scale precipitation. Initial experiments using the more advanced double-moment cloud microphysics in a newer version of WRF-ARW (3.4.1) will be discussed in Section 4.

\section{Model Case Studies for Windshear due to Sea Breeze and Localised Wind Convergence}

3.1. Sea-Breeze-Induced Windshear (February 25, 2011). Windshear events occur mostly under nonrainy weather condition in HKIA. Under the insolation, sea-breeze circulation forms over the Pearl River Estuary and in the vicinity of the airport during the late morning or early afternoon. For example, on February 25, 2011, a ridge of high pressure over eastern China brought light to moderate easterly winds over HK (Figure 2(a)) and the coastal region of Guangdong. A sea breeze was established where the wind convergence was located just over the western end of the runway (Figure 2(b)) during 12-13 HKT (04-05 UTC; $\mathrm{HKT}=\mathrm{UTC}+8$ hours). Significant windshear resulting in a headwind gain of 15-20 knots was encountered by more than 10 aircraft landing from southwest over the north runway (07LA corridor). Figure 3(a) shows the forecast from the routine $2 \mathrm{~km} \mathrm{NHM}$. The backing of light to moderate easterly winds to west-to-northwesterly winds over the western adjacent waters was captured by the model in the 4-hour model forecast. However, the wind convergence was off from the western end of HKIA. Figure 3(b) shows the forecast from HKA-AVM. It could be seen that the AVM run demonstrated some improvement in the forecast location of the wind convergence. The finer-resolution model with a more realistic representation of terrain and the land-sea contrast improved the forecast location of wind convergence.

It will be useful to provide advance alert to pilots and aviation users if the model can provide indications of abrupt headwind changes upon landing (or take-off) or occurrence of significant windshear situation. Figure 4 shows the simulated headwind profile along glide path from HKA-AVM (green line) for a selected aircraft. The numerical simulation was also repeated using NHM with the same grid size $(200 \mathrm{~m})$ to generate the headwind profile for comparison. The headwind profiles are produced using the direct model outputs of the 3-dimensional wind components and projected along the glide path of aircraft. The corresponding aircraft headwind profile and the altitudes of the glide path from 04:43:50 to 04:45:20 UTC are shown by the red line and purple line, respectively. It should be noted that the forecast profiles from HKA-AVM and NHM are taken from the snapshots of respective model prediction at 05:00 UTC $(T+4 \mathrm{~h}$ forecast). The headwind profiles among the model forecasts and actual time trace show good agreement with each other. The two model forecasts indicate an earlier change of headwind to tailwind (04:44:15 UTC to 04:44:40 UTC) than the actual at 04:44:50 UTC. The differences between the results of HKA-AVM and NHM are small in general, but the HKA-AVM is able to better capture the abrupt jump in the magnitudes of headwind near the touch-down point (i.e., flight altitude near zero). Both the fine-resolution model simulations demonstrate some potential to capture windshear and simulate the effects on headwind changes experienced by the aircraft.

3.2. Impact of Model Physics in Forecast of Localized Wind Convergence (June 25, 2011). The development of local wind convergence over HKIA is often complicated by the effect of surrounding terrain that provides localized sensible heat exchange through near-surface processes and blocking of low-level flow to form microscale circulation patterns. An example can be seen from another windshear event that occurred in the early afternoon of June 25,2011 . Throughout the morning of June 25 , a moderate southwesterly wind prevailed over Lantau (Figures 5(a) and 5(b)). The winds over the eastern adjacent waters of HKIA gradually veered to easterly or southeasterly during 12 to $13 \mathrm{HKT}$, and windshear (Figures 5(c) and 5(d)) was encountered by a number of aircrafts descending from northeast and landing at the north runway (25RA corridor). 


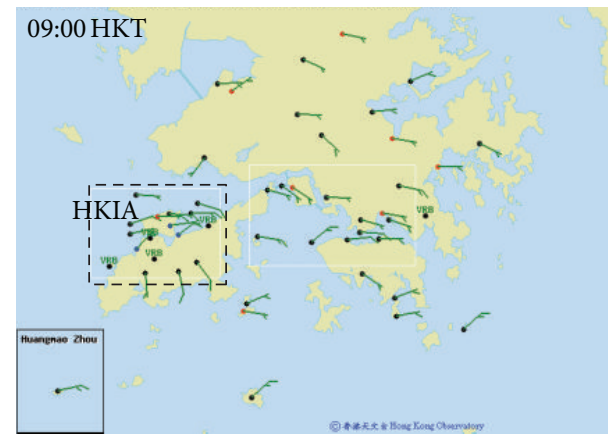

(a)

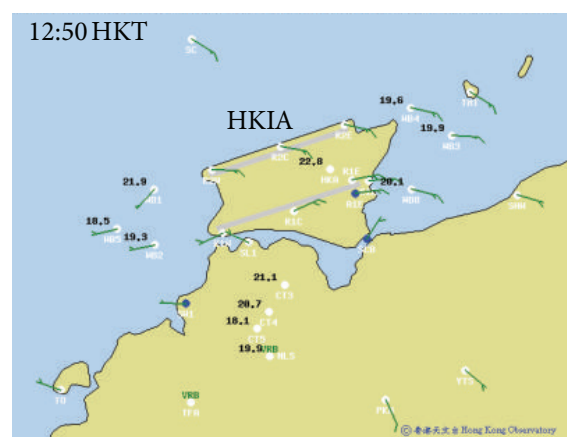

(b)

FIGURE 2: AWS wind observations at (a) 09:00 HKT and (b) 12:50 HKT on February 25, 2011. Area of right-side figure is marked in dashed line in (a).

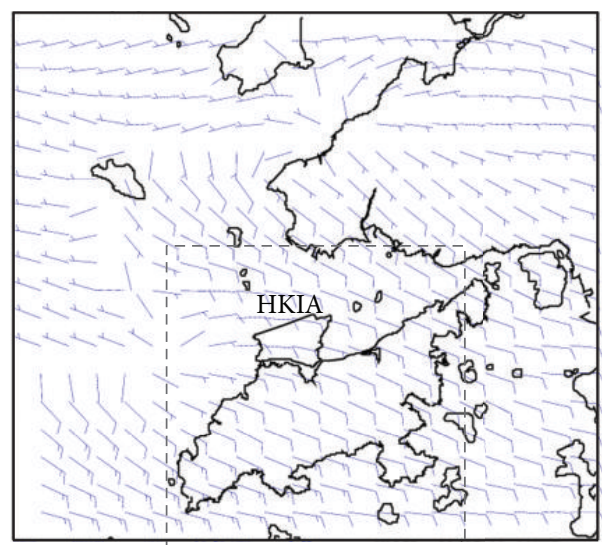

(a)

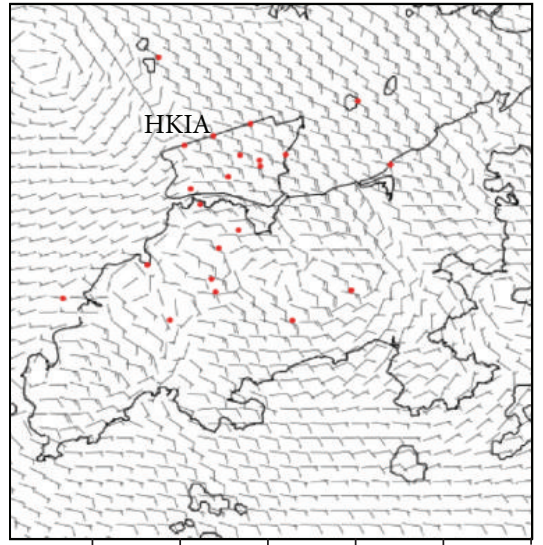

(b)

FIgURE 3: (a) Four-hour forecast of surface wind and sea-level pressure (contour line) from $2 \mathrm{~km}$ NHM run at 0100 UTC February $25,2011$. (b) Four-hour wind forecast from HKA-AVM. Area of (b) is marked in dashed line in (a). Locations AWS stations shown in Figure 2 are marked as dots in (b).

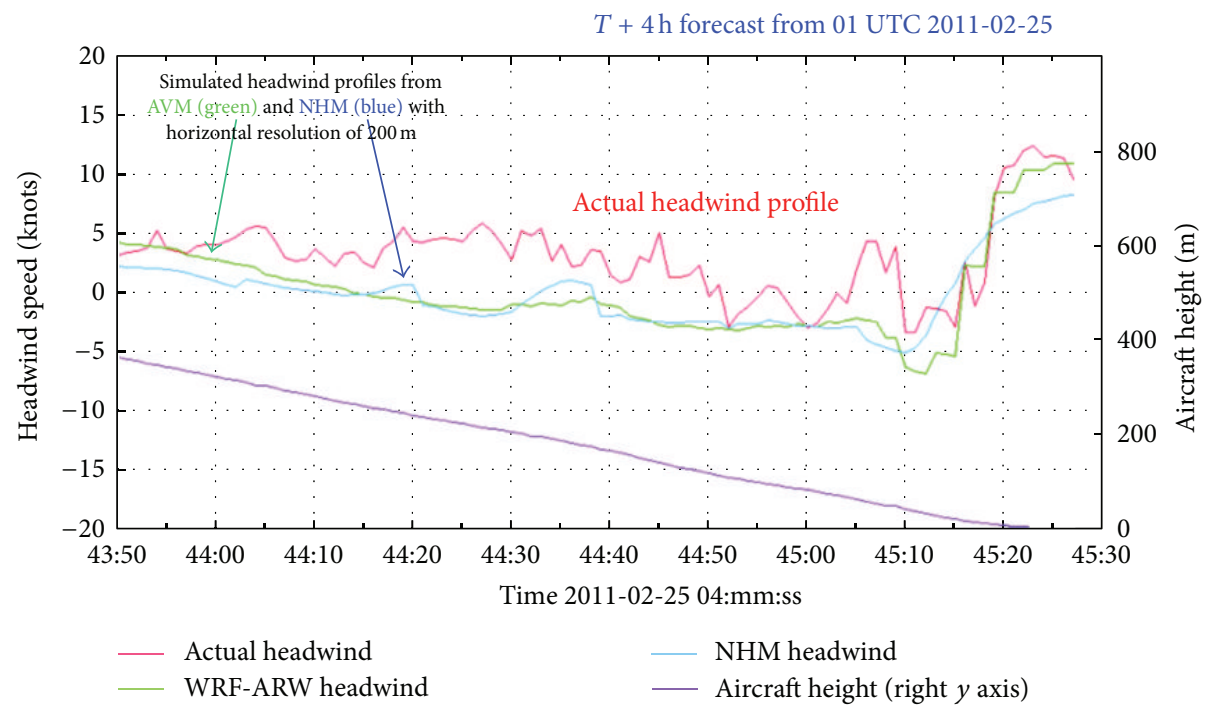

Figure 4: Simulated headwind profile from HKA-AVM forecast (green) along the glide path (purple line) and actual flight data (red). For comparison, blue line shows the headwind profile from NHM running at the same horizontal resolution (grid size at $200 \mathrm{~m}$ ). 


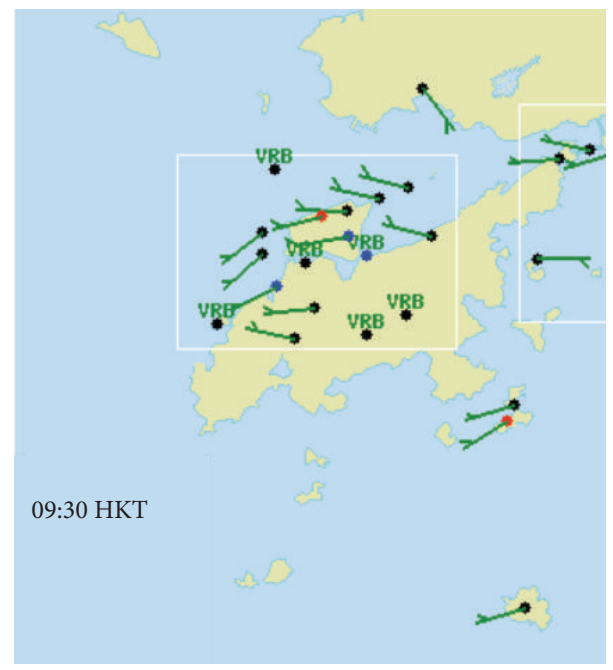

(a)

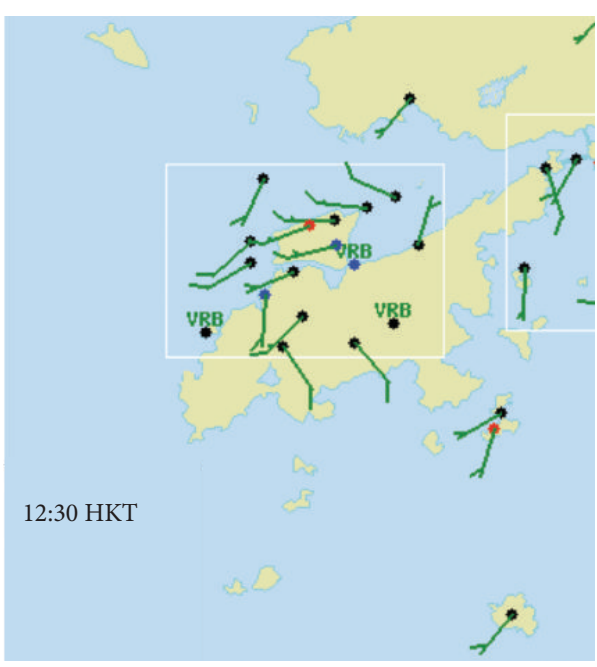

(c)

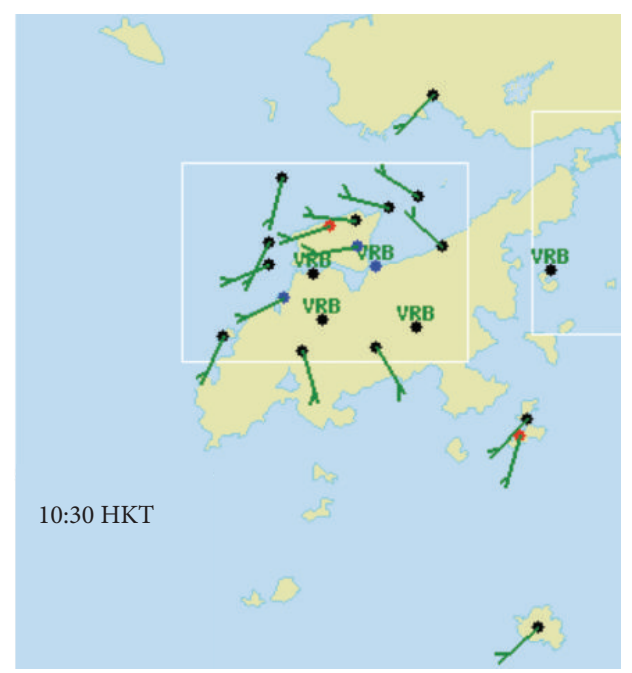

(b)

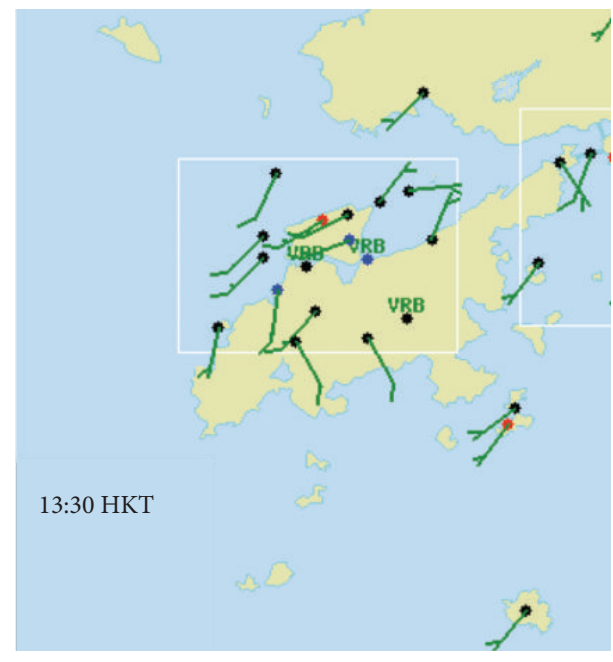

(d)

FIgURE 5: AWS wind observations on 09:30, 10:30, 12:30, and 13:30 HKT on June 25, 2011.

The veering of the winds from southwesterly in the morning to westerly over the region to the northeast of HKIA was captured in the $2 \mathrm{~km} \mathrm{NHM}$ forecasts (not shown). Using HKA-AVM (Figure 6(a)), the veering of winds became more pronounced due to better model resolution of small scale features of wind flow. However, the wind convergence over the eastern end of the runways could not be reproduced.

To address the problem on the development of smallscale wind features, a series of numerical experiments were attempted by inspecting effects on surface wind and temperature forecasts over HKIA based on all available options of near-surface physics, boundary layer process, and land surface model options. In summary, some selected combination of these model physical processes could improve the model forecast of the timing of changes in wind direction or spatial and temporal variation of temperatures over HKIA. For instance, the use of recent longwave and shortwave radiation schemes based on the RRTMG (a new version of the Rapid Radiative Transfer Model for more efficient and accurate computation of radiation process) generally improved the forecast temperature over HKIA and the Lantau Island, possibly due to a better treatment of cloud overlap effect and inclusion of multiple bands of shortwave and longwave radiation. The use of a different land surface scheme by switching from the basic 5-layer thermal diffusion model to a more sophisticated land surface model (LSM) such as the NCEP Noah LSM and RUC LSM resulted in a slight positive impact on the model temperature forecast (not shown). The sensitivity tests were also performed using different model data on the soil temperature and soil moisture. They included the NCEP global model (GFS) forecast of horizontal resolution at 0.5 degree in latitude/longitude and a higher resolution data products from the ECMWF model forecast at 0.125 degree in latitude/longitude. However, the resulting changes 


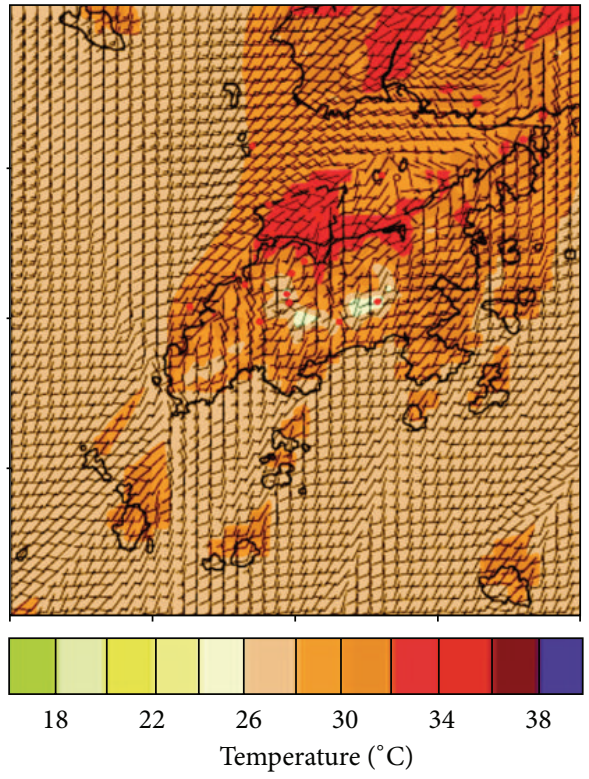

(a)

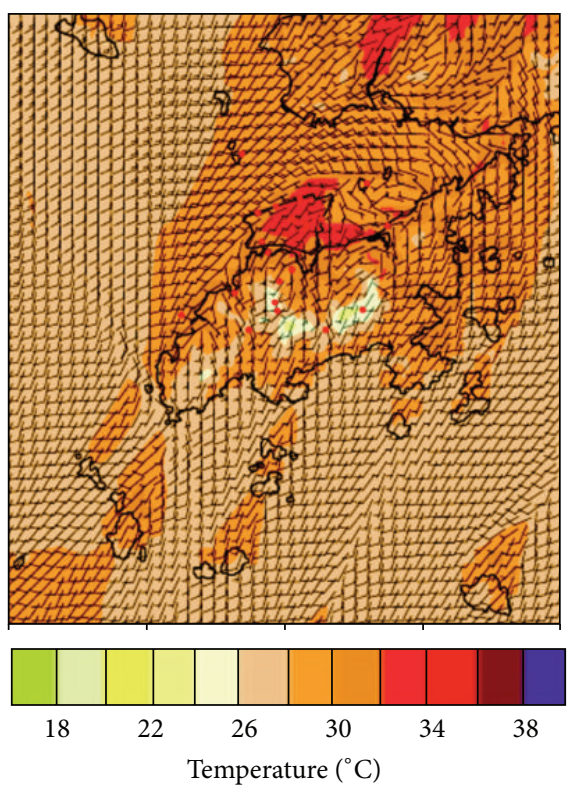

(b)

Figure 6: Forecast wind and temperature from HKA-AVM from (a) original and (b) new settings of scheme. Refer to Section 3.2 for details. The locations of AWS over HKIA and the Lantau Island are shown in red dots.

in forecast temperature and winds over HKIA were relatively small. Further study will be conducted to investigate the impact of the model data under different weather conditions.

The impact on wind prediction was found to be rather marginal using the existing or newly available PBL schemes in WRF-ARW (e.g., Mellor-Yamada-Nakanishi-Niino thirdorder turbulence closure model as adopted in NHM) with corresponding compatible near-surface scheme to diagnose the surface wind, temperature, and moisture. That limitation is possibly attributed to the insufficient representation of turbulent eddies such that the PBL schemes in WRF (and other mesoscale NWP models) are suitable only for model horizontal resolution up to one or a few kilometers.

In recent versions of WRF, a Large-Eddy Simulation (LES) model has been incorporated in the code. LES has been widely applied to study turbulence as well as its coherent structures and statistics within PBL. Using this new option (with 3-dimensional diffusion term, 1.5 order TKE closure, RRTMG shortwave and longwave, and the default MM5 similarity near-surface process), the same forecast of wind distribution over HKIA is depicted in Figure 6(b), which shows a quite encouraging result on the model simulated windshear feature in terms of more realistic location and timing of localized wind convergence and associated microscale anticyclone off the HKIA. Moreover, it should be noted that the simulated wind pattern was quite sensitive to the choice of near-surface process (e.g., changing from MM5 similarity to Eta model type), as well as the method to calculate the momentum flux, heat flux, and moisture flux in the WRF-LES. The forecast speed of southwesterly wind could be strengthened using these choices such that the formations of local-scale anticyclone and wind convergence were suppressed.

\section{Significant Convection Forecasts Using AVM}

4.1. Widespread Quasi-Stationary Significant Convection over HKFIR (18 September 2011). PRD-AVM was applied to simulate a significant convection event that occurred on September 18, 2011. During the morning, convection clusters developed over the coastal waters under the presence of a broad low pressure areas and convergence of easterly airstream along the coast of Guangdong. The radar echoes became more organized and formed into broad bands of significant convection. They were quasi-stationary and blocked the passage of aircraft from the south in the HKFIR. A series of images showing radar CAPPI reflectivity at $3 \mathrm{~km}$ altitudes is given in Figure 7.

The PRD-AVM forecast was initiated for 2300 UTC September 17, 2011. Its initial and boundary conditions were based on the forecasts of $2 \mathrm{~km}$ NHM run at 2200 UTC to ensure a better input to AVM in terms of sufficient spin up of moisture and other model forecast elements. The simulated maximum reflectivity maps from PRD-AVM in 0000-0500 UTC are given in Figure 7. The hourly accumulated rainfall forecasts from $2 \mathrm{~km}$ NHM are also shown for comparison.

The WSM-5 scheme employed in PRD-AVM produced a reasonable trend of convection development. The "simulated radar echoes" were found to intensify and organize into a significant convection cluster in 3 to 6 hours ahead. However, the location of the whole forecast convection system was found to locate more southwest to the actual shown in the radar imagery. Model simulated radar reflectivity of $50 \mathrm{dBZ}$ (or above) together with a higher amount of precipitation was obtained when compared to the forecasts from the $2 \mathrm{~km}$ 

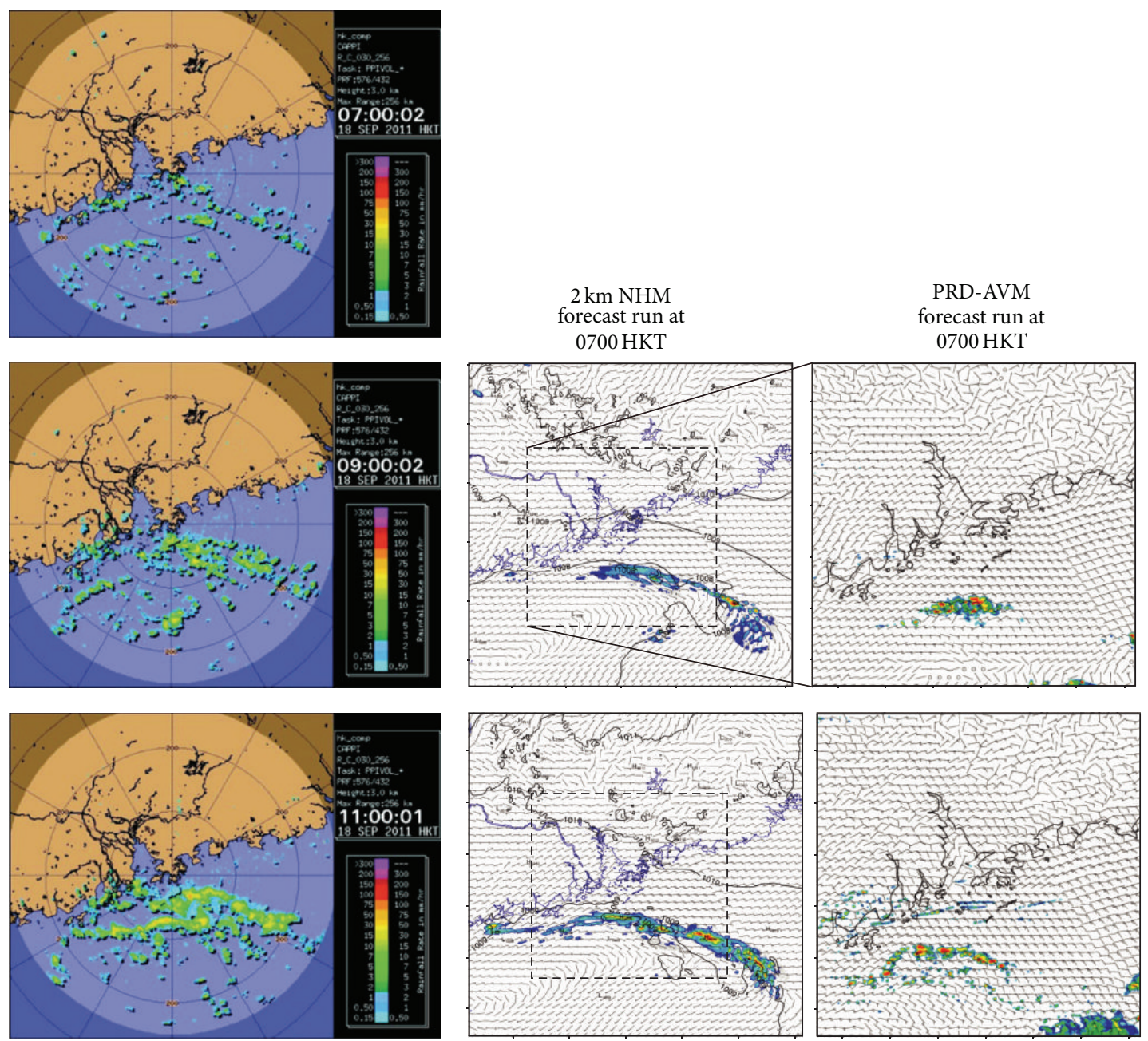

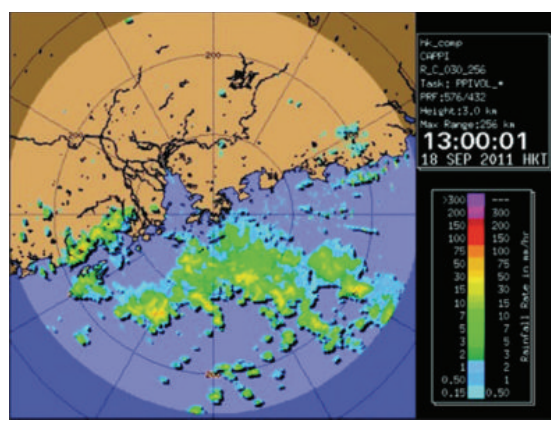

(a)

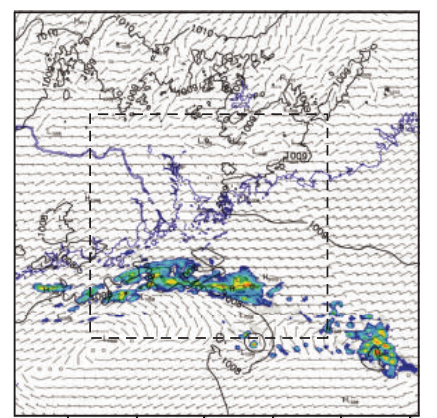

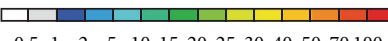
(mm)

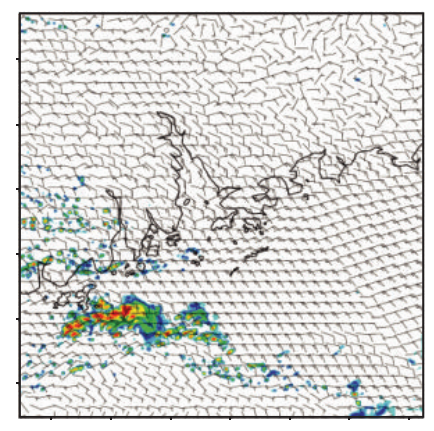

51015202530354045505560657075 Max reflectivity (dBZ)

(c)

FIGURE 7: Radar CAPPI reflectivity on $3 \mathrm{~km}$ at 07:00, 09:00, 11:00, and 13:00 HKT September 18, 2011. 2 km NHM hourly accumulated rainfall forecast with surface winds in middle column. Simulated radar reflectivity and surface winds from PRD-AVM are shown in the right column; the figure areas are marked in dashed box in $2 \mathrm{~km}$ NHM charts.

NHM (not shown). In this case, $2 \mathrm{~km}$ NHM showed a more realistic result in terms of a broader coverage of rain bands. It was possibly due to a larger size of domain in $2 \mathrm{~km}$ NHM that better represented the low-pressure area and the convection system over the coastal waters.
4.2. Initiation of Isolated Thunderstorms (May 20, 2012)Comparison with Different Advanced Cloud Microphysics Parameterizations. Summertime heat thunderstorms, in particular associated with the sea-breeze convergence, often develop rapidly into organized rainstorms. Accurate forecasts 

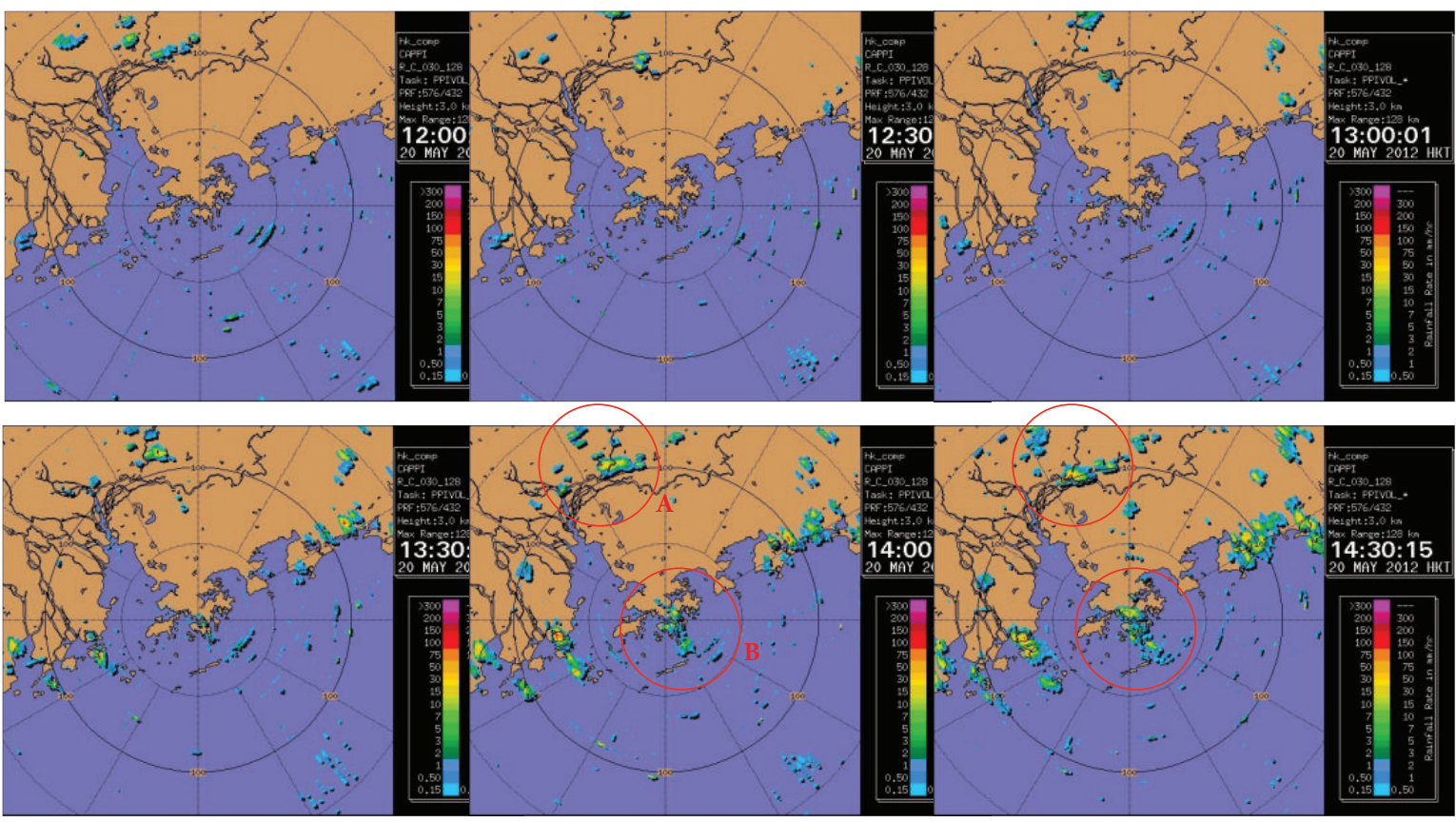

FIGURE 8: Radar reflectivity image from 12:00 to 14:30 HKT on May 20, 2012. Thunderstorm developments over inland Guangdong and the urban areas of $\mathrm{HK}$ are labeled in $\mathrm{A}$ and $\mathrm{B}$.

for their initiation and development are challenging due to the uncertainties of mesoscale processes. For instance, under the condition of weak pressure gradient, generally light winds and a conditionally unstable environment in the morning on May 20, 2012, development of wind convergence over the local territory and coastal areas occurred in the early afternoon leading to rapid development of thunderstorm cells. A sequence of radar CAPPI reflectivity images during 12 to 14 HKT is shown in Figure 8. With more widespread development found over the northern part of the New Territories, heavy rain occurred and lasted for a few hours till the evening.

Forecast charts of simulated radar reflectivity with surface winds from the PRD-AVM run initialized at $0800 \mathrm{HKT}(0000$ UTC) May 20, 2012, are shown in Figure 9. The WSM-5 cloud microphysics scheme was used. Under a rather weak synoptic forcing environment, convergence of winds developed due to the sea breeze over the coastal areas and surface heating under insolation over the inland regions. The initiation of convective cells was forecast by PRD-AVM over these convergence zones where instabilities were also found. The development of intense thunderstorms over inland Guangdong (area A) and HK (area B) was captured reasonably in terms of location and trend. In WRF-ARW, several bulk microphysics schemes ("mp_physics" option) have been made available since the release of version 2 for predicting the specific humidity of cloud hydrometeors including both water and ice components. In particular, Hong et al. [7] compared the performance of WRF single moment (WSM) 3-class, 5-class, and 6-class to simulate a mesoscale convective storm. It was found that three schemes generally demonstrated similar performance in terms of rainfall distribution and WSM-5 tended to produce more realistic rainfall intensity due to inclusion of mix-phased hydrometeors and a deeper layer of melting and freezing processes. Using the more complex WSM-6, which includes the specific humidity of graupel in the governing equations, a more localized distribution of peak rainfall was simulated owing to the fall out of graupel as well as rain water. However, the scheme showed a bias for overpredicting the coverage of light rain.

Recently, more sophisticated double-moment cloud microphysics schemes have been implemented in WRFARW that can predict both the mixing ratio and number concentration of hydrometeor species, such as cloud droplets, cloud ice, rain and snow, to improve the representation of cloud processes in forecast of convective weather phenomena. Three numerical experiments were performed using the WRF-ARW 3.4 using the WDM-6 (WRF 6-class double moment scheme [8]), Morrison double-moment scheme [9] and Milbrandt-Yau double-moment scheme [10]. Figure 10 shows the forecast reflectivity maps in 4-6 hours of forecasts where the local sea-breeze-induced convergence and thunderstorms were initiated. Generally, all the three schemes were capable to predict the development of the localized simulated radar reflectivity with peak intensity at $45 \mathrm{dBZ}$ or above. They have differences in spatial distribution and locations though the surface wind field forecast in terms of its wind convergence was quite similar (not shown). For instance, the forecasts from WDM-6 showed the most intense and localized organization of high reflectivity echoes or storm cells compared to Morrison and Milbrandt-Yau schemes. The development of the thunderstorms was found to be about 2 hours earlier than the other two schemes. It was discussed in [7] that the WDM-6 was able to provide an improved treatment of the variability in cloud and rain number concentrations in order to ameliorate the generation 


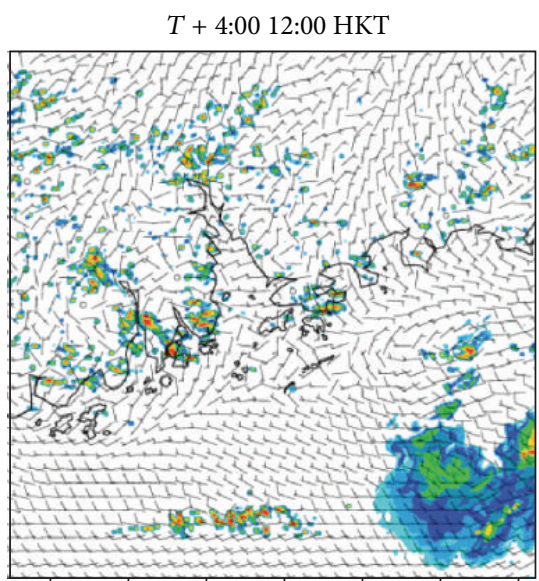

(a)

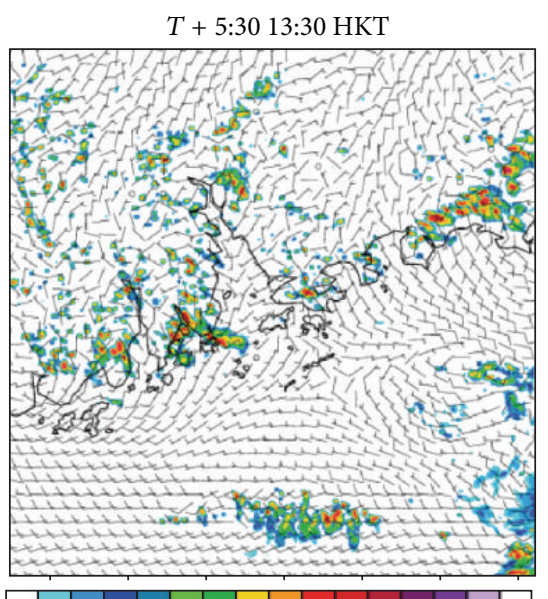

51015202530354045505560657075 Reflectivity (dBZ)

(d)

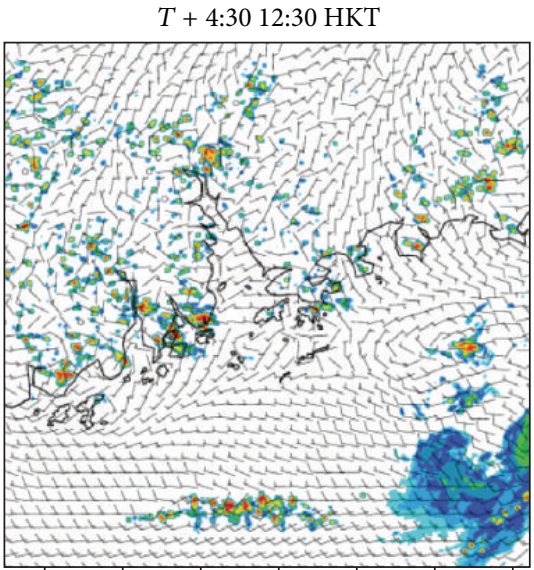

(b)

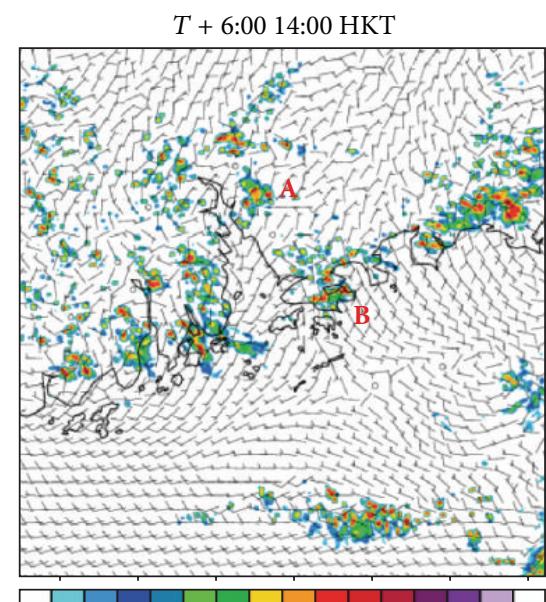

51015202530354045505560657075 Reflectivity (dBZ)

(e)

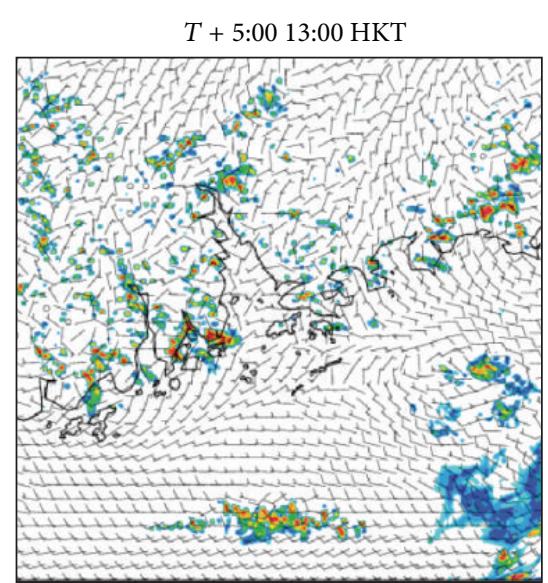

(c)

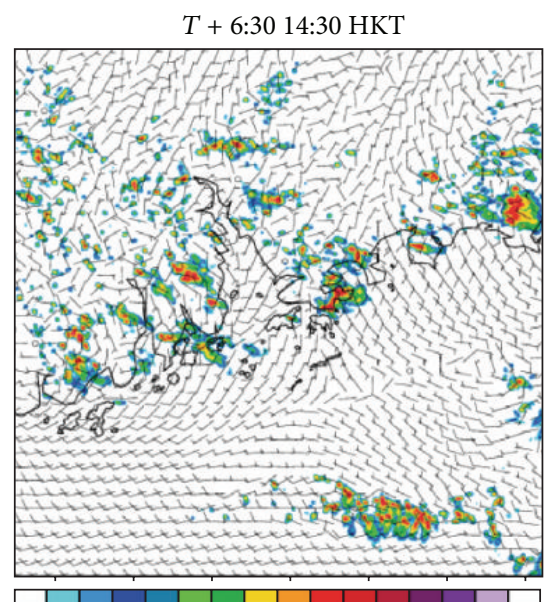

51015202530354045505560657075 Reflectivity (dBZ)

(f)

FIGURE 9: Simulated radar reflectivity from PRD-AVM run at 0000 UTC (0800 HKT) May 20, 2012. The development of convective cells in $\mathrm{A}$ and $\mathrm{B}$ by the model forecasts at 14:00 HKT is indicated for comparison.

of widespread light rain as found in its single moment version (WSM-6).

In case for Morrison and Milbrandt-Yau schemes, they have similar forecasts in the distribution of simulated reflectivity. In terms of timing and location of development, the Milbrandt-Yau scheme predicted both the thunderstorms ( $\geq 35 \mathrm{dBZ}$ ) at $\mathrm{A}$ and $\mathrm{B}$ to occur during 13-14 HKT that were more coherent with the radar images (Figure 8). Additionally, the Milbrandt-Yau scheme better resembled the convection over the coastal waters in $T+4$ hour of forecast that were also present in WSM-5 (Figure 9). More studies will be performed in future to understand the mechanisms and the characteristics of the three double moment schemes.

\section{Concluding Remarks}

In this paper, the development of AVM is discussed. AVM is designed to enhance the capability of NWP to support the aviation forecast in the Hong Kong Observatory. The model has been successfully implemented for trial experiments to simulate windshear events, sea-breeze convergence, and significant convections. Sensitivity experiments using different model physical processes have been attempted in order to obtain a feasible setup and configuration of AVM in forecasting the local or microscale weather phenomena near HKIA. They show encouraging results and thus favorable for routine runs in rapid-update cycle configuration subject to available computing resources. However, there are yet a number of limitations to solve as elaborated in the following paragraphs.

The $200 \mathrm{~m}$ HKA-AVM could reproduce more realistic wind flow and forecasts for HKIA compared to the current operational mesoscale NWP system ( $2 \mathrm{~km}$ NHM). Though a number of choices of physical parameterization process for PBL, near-surface process, land surface models, and cloud microphysics from WRF-ARW have been studied or adopted in other high-resolution NWP studies, they may not be fully applicable for the fine-resolution simulation with horizontal resolution at $200 \mathrm{~m}$. For instance the $\mathrm{PBL}$ process, land 
$T+4: 00$ 12:00 HKT
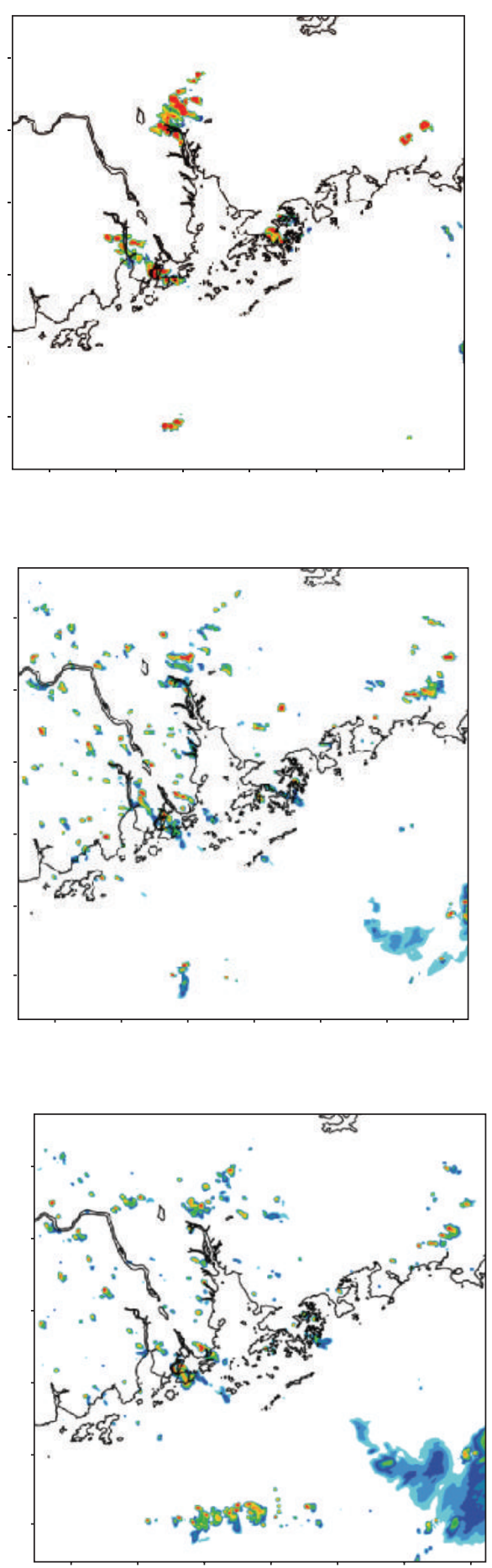

51015202530354045505560657075 Reflectivity (dBZ)
$T+5: 00$ 13:00 HKT

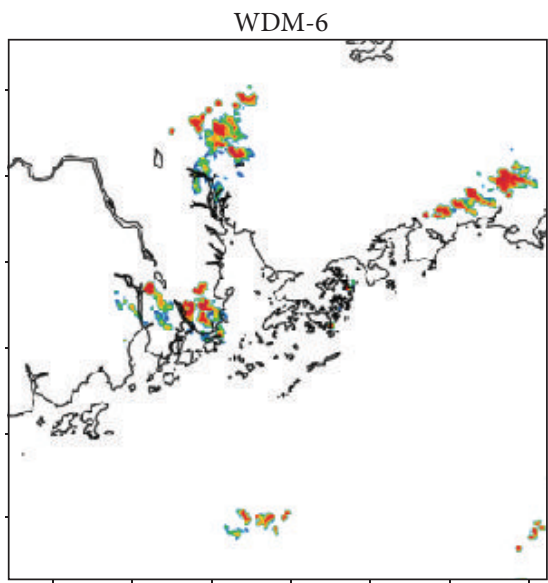

(a)

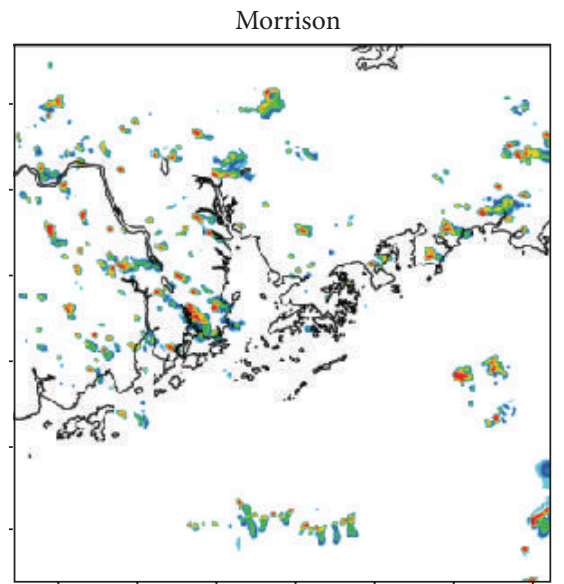

(b)

Milbrandt-Yau

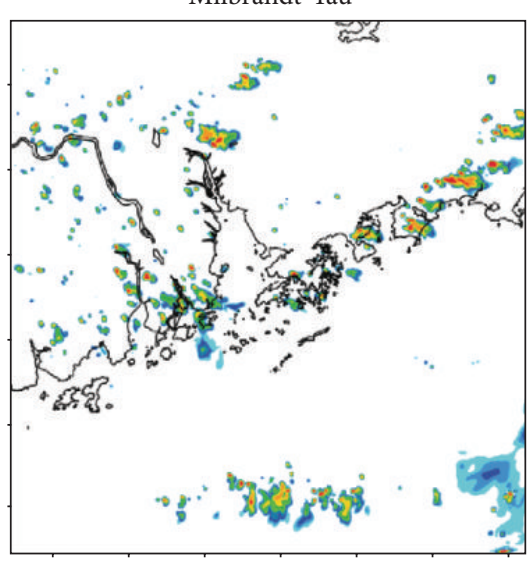

51015202530354045505560657075 Reflectivity (dBZ)
$T+6: 00$ 14:00 HKT
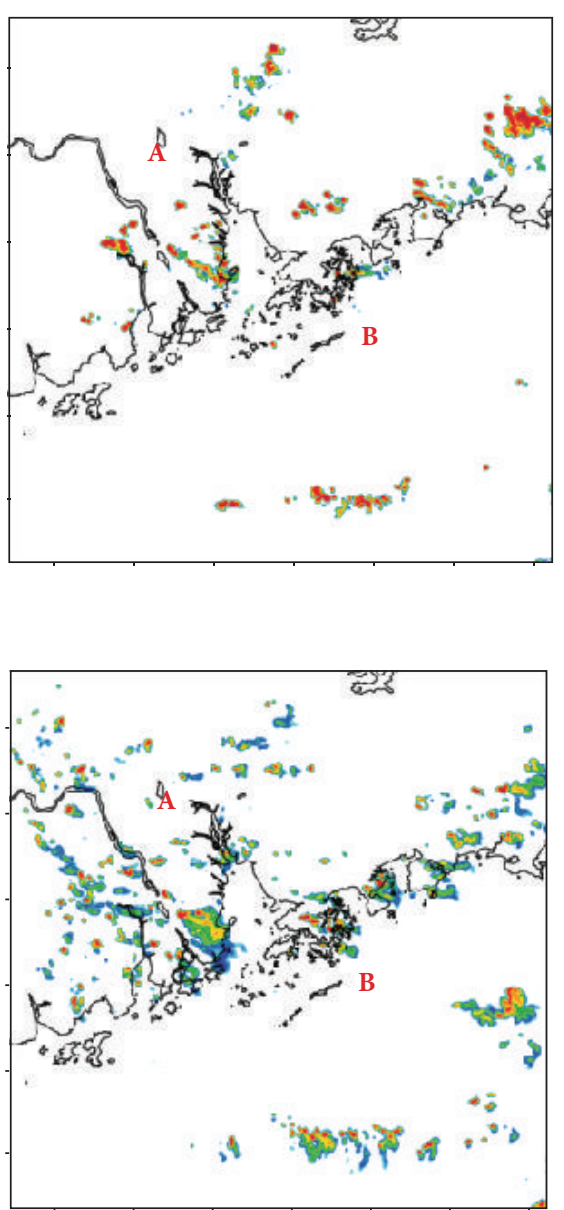

(c)

FIGURE 10: Simulated radar reflectivity from PRD-AVM run at 0000 UTC (0800 HKT) May 20, 2012 using different double-moment cloud microphysics scheme: (a) WDM-6, (b) Morrison, and (c) Milbrandt-Yau. Development of convective cells near Guangzhou (A) and over Hong Kong (B) in the model forecasts is shown. 
surface model, and even the correct specification of the land surface type are important to accurately simulate the finescale wind field in HKIA. Secondly, the domain size of PRDAVM may be too limited to forecast the development of the convective systems near the boundary, where the boundary data are provided from $2 \mathrm{~km}$ NHM. To mitigate the inconsistency, we may consider extending the domain of PRDAVM subject to computation resources or including another outer model with coarser resolution (e.g., grid spacing at 1 or $2 \mathrm{~km}$ ) using two-way nesting for a more consistent update of forcing in the model boundary. In fact, two-way nesting was attempted in the initial setup of WRF but found to be numerically unstable occasionally. With the newer version of code available (version 3.4), the two-way nesting would be explored again to check the code robustness and possible gain in computation speed over the existing one-way nesting method (a.k.a. nest-down, "ndown" approach).

The whole AVM system is currently initialized by interpolation of the $2 \mathrm{~km}$ NHM forecasts. Though the " $3: 1$ ” nesting ratio (2000 $\mathrm{m}$ in NHM versus $600 \mathrm{~m}$ in PRD-AVM) was found to be a viable choice from the results of simulation experiments, it is no doubt that the model initialization, especially some spin-up problems linked to the cloud microphysics could be alleviated through an implementation of data assimilation (DA) in future. The implementation of AVM-DA system is not trivial, since the current configuration of data assimilation using the variational methods (3DVAR or 4DVAR) requires a well-tuned background covariance model. The correlation of the analysis control variables is specified based on physical balances in synoptic and subsynoptic scales of processes to generate an optimal model analysis as the initial condition. Additionally, the tangent linear and adjoint models of WRF may not be sufficient to represent the mesoscale and cloud microphysical processes. This would be pursued in the future research studies on the performance of the variational data assimilation of the WRFARW, including the technique and related tuning, if available, for constructing a suitable DA system for PRD-AVM and HKA-AVM.

\section{Acknowledgments}

Part of the research work in this paper was conducted by the second author during his attachment to HKO in 2011-2012. Thanks are also due to Drs. Beta C. L. Yip and Ivy K. Y. Wong for providing technical supports in setting up an experimental version of AVM system using WRF-ARW 3.2.1.

\section{References}

[1] P. W. Chan and T. C. Cheung, "Microscale simulation of terraindisrupted airflow around the Hong Kong International Airport (HKIA) - comparison of results between numerical models," in Proceedings of the 10th Annual WRF Users' Workshop, Boulder, Colo, USA, June 2009.

[2] W. K. Wong, "Development of operational rapid update non-hydrostatic NWP and data assimilation systems in the
Hong Kong observatory," in Proceedings of the 3rd International Workshop on Prevention and Mitigation of Meteorological Disasters in Southeast Asia, Beppu, Japan, March 2010, http://www.hko.gov.hk/publica/reprint/r882.pdf.

[3] K. Saito, T. Fujita, Y. Yamada et al., "The operational JMA nonhydrostatic mesoscale model," Monthly Weather Review, vol. 134, no. 4, pp. 1266-1298, 2006.

[4] W. K. Wong, M. K. Or, P. W. Chan, and C. M. Cheng, "Impact of radar retrieval winds on data assimilation and forecast of a mesoscale convective storm using non-hydrostatic model," in Proceedings of the 14th Conference on Mesoscale Process, American Meteorological Society, Los Angeles, Calif, USA, August 2011.

[5] W. C. Skamarock, J. B. Klemp, J. Dudhia et al., "A description of the advanced research WRF version 2," NCAR Tech Notes468+STR, 2005.

[6] X. Z. Liang, M. Xu, X. Yuan et al., "Regional climate-weather research and forecasting model," Bulletin of the American Meteorological Society, vol. 93, pp. 1363-1387, 2012.

[7] S. Y. Hong, K. S. Lim, Y. H. Lee et al., "Evaluation of the WRF double-moment 6-class microphysics scheme for precipitating convection," Advances in Meteorology, vol. 2010, Article ID 707253, 10 pages, 2010.

[8] K. S. S. Lim and S. Y. Hong, "Development of an effective double-moment cloud microphysics scheme with prognostic cloud condensation nuclei (CCN) for weather and climate models," Monthly Weather Review, vol. 138, no. 5, pp. 1587-1612, 2010.

[9] H. Morrison, G. Thompson, and V. Tatarskii, "Impact of cloud microphysics on the development of trailing stratiform precipitation in a simulated squall line: comparison of one- and twomoment schemes," Monthly Weather Review, vol. 137, no. 3, pp. 991-1007, 2009.

[10] J. A. Milbrandt and M. K. Yau, "A multimoment bulk microphysics parameterization. Part I: analysis of the role of the spectral shape parameter," Journal of the Atmospheric Sciences, vol. 62, no. 9, pp. 3051-3064, 2005. 

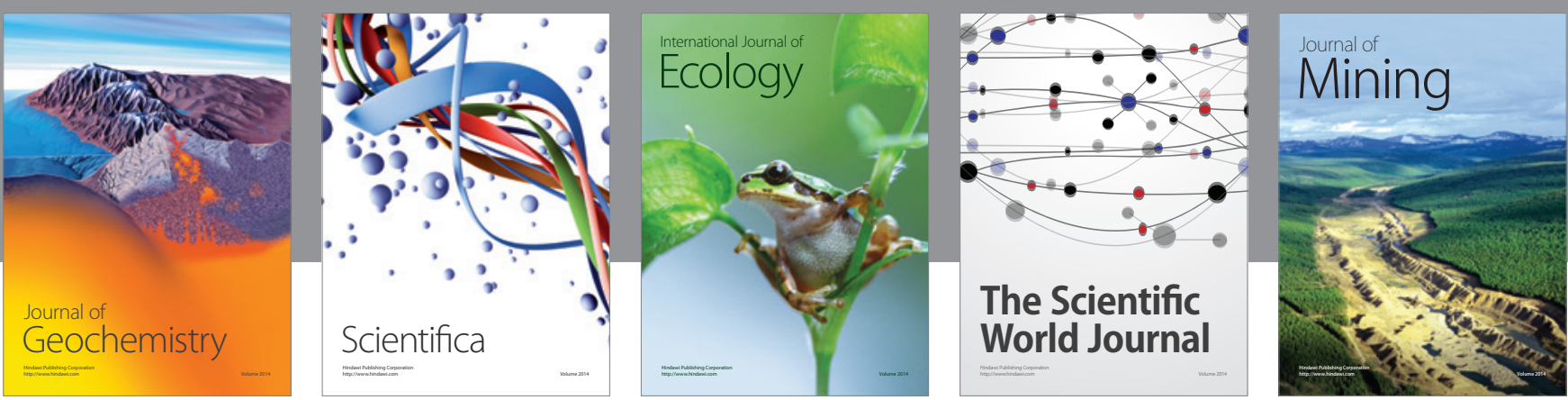

The Scientific World Journal
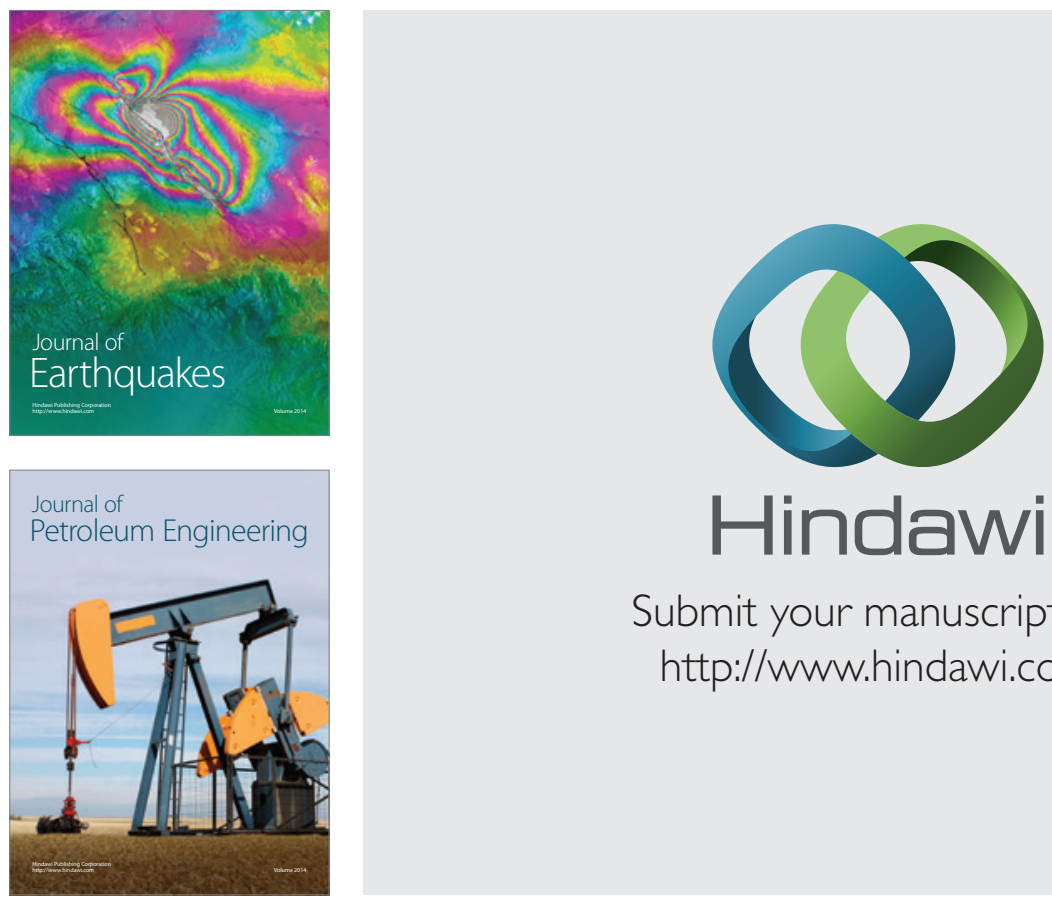

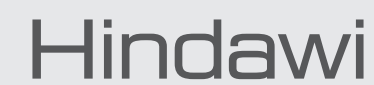

Submit your manuscripts at

http://www.hindawi.com
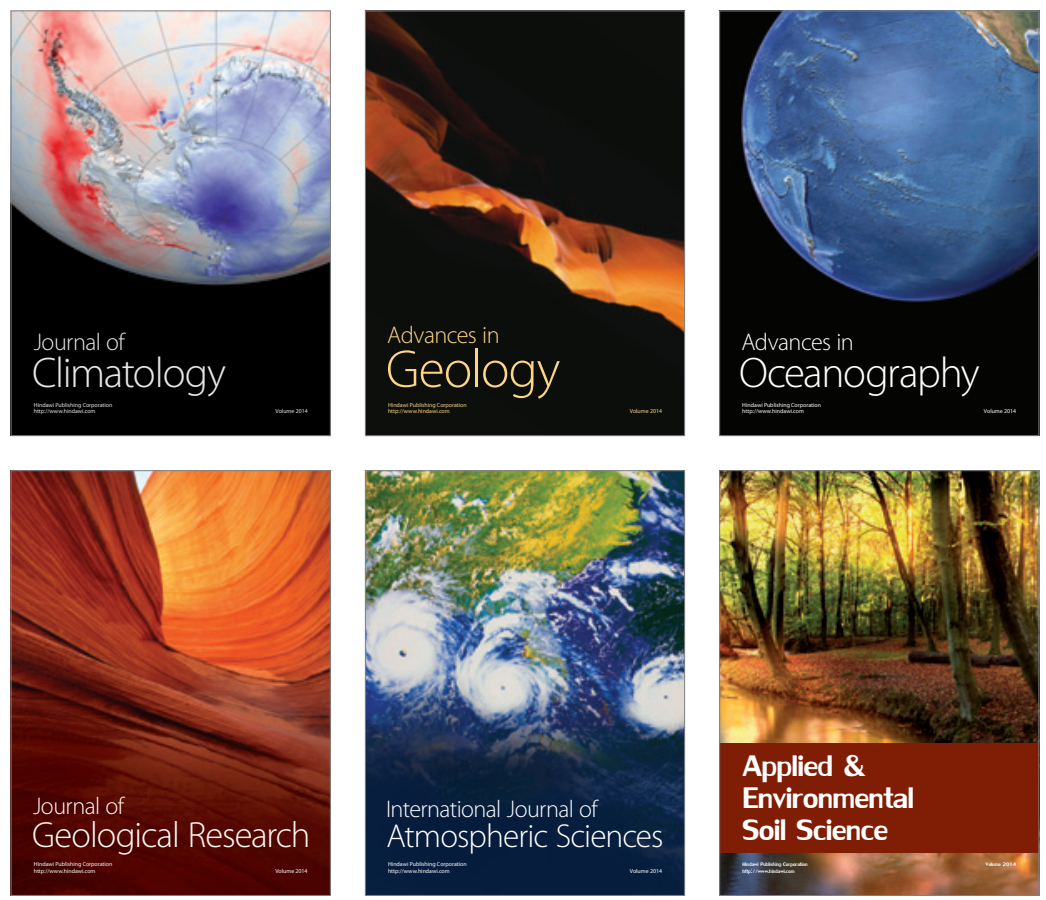
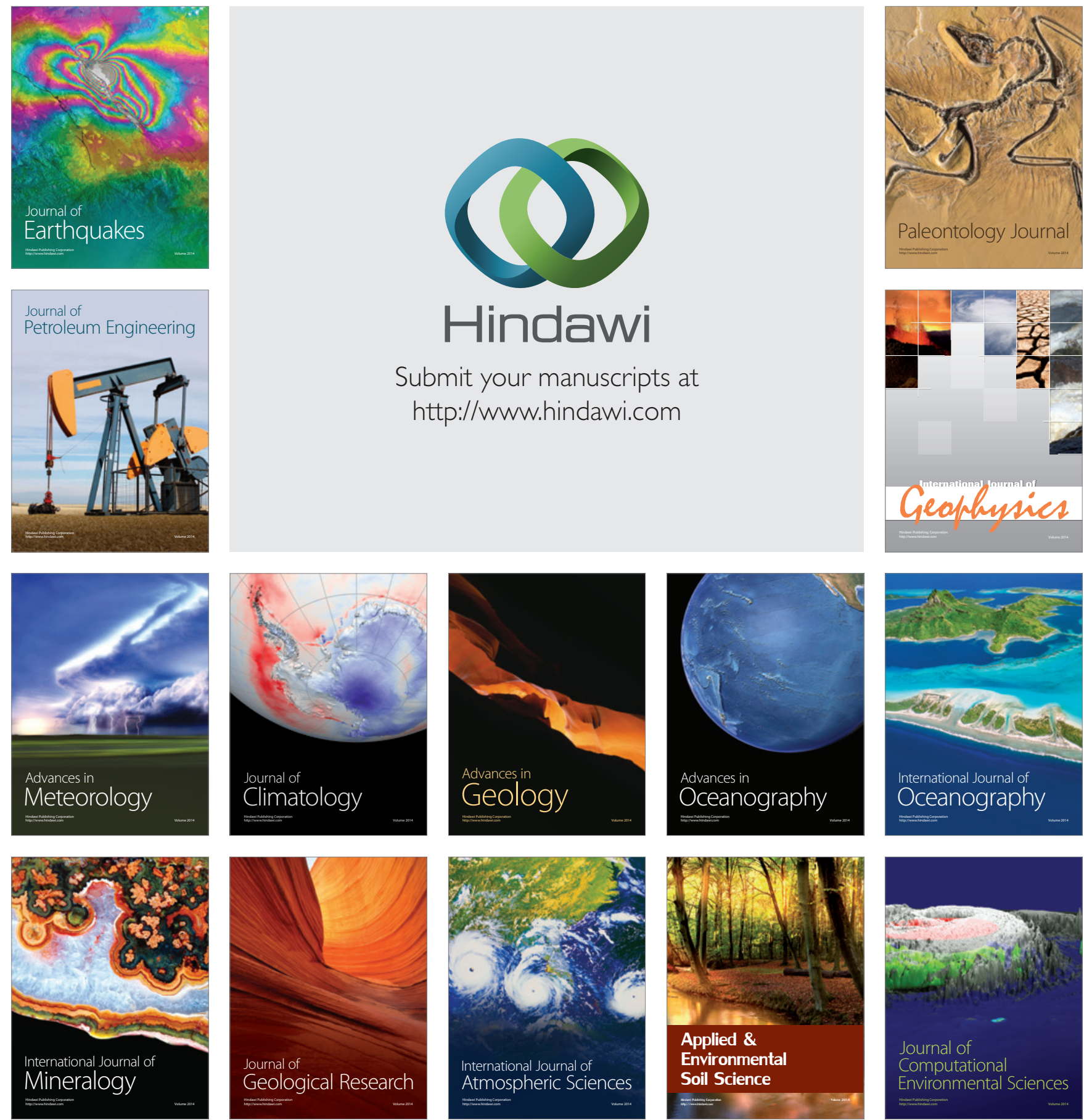